\title{
Uso do ácido mandélico no tratamento de hipercromias pós- inflamatória: uma revisão de literatura
}

O cuidado com a pele é algo cada vez mais frequente nos dias atuais, estando a hiperpigmentação entre as primeiras queixas dos pacientes em procedimentos estéticos. $\mathrm{O}$ ácido mandélico é um alfa-hidroxi-ácido amplamente utilizado no tratamento de hipercromias por sua eficaz ação clareadora que pode ser utilizada em todos os fototipos de forma segura. Por conter uma molécula de alto peso, o ativo permeia de forma lenta na pele agindo na síntese de melanina. $O$ presente estudo visa explicar resumidamente a estrutura da epiderme e do melanócito, a síntese da melanina como responsável pela pigmentação cutânea e a ação do peeling mandélico como ativo despigmentante. A metodologia utilizada foi o estudo bibliográfico que consiste na coleta de informações, baseando-se em estudos pré-existentes disponíveis em livros, artigos e sites inerentes à área da saúde. Após a seleção do material de estudo, foi realizado a leitura, análise minuciosa e interpretação das informações, dando subsídio para o fichamento de dados e consequente fundamentação teórica. A partir da análise das informações pode-se concluir que as hipercromias são resultantes de diversos fatores e que o ácido mandélico é uma opção menos agressiva para o tratamento dessa disfunção, apresentando resultados satisfatórios. Por se tratar de uma molécula com alto peso, sua permeação é mais lenta e uniforme, agindo como um estimulador de colágeno, no entanto, seu uso indiscriminado pode acarretar queimaduras, equimoses e outros efeitos adversos, tornando aconselhável sua administração por pessoal capacitado.

Palavras-chave: Epiderme; Hipercromias; Melanogenese; Ácido Mandélico.

\section{Use of mandelic acid in the treatment of postinflammatory hyperchromias: a literature review}

\begin{abstract}
Skin care is something more and more frequent nowadays, with hyperpigmentation being among the first complaints of patients in aesthetic procedures. Mandelic acid is an alpha-hydroxy-acid widely used in the treatment of hyperchromias due to its effective lightening action that can be used in all phototypes safely. Because it contains a high-weight molecule, the active agent slowly permeates the skin acting on the synthesis of melanin. The present study aims to briefly explain the structure of the epidermis and melanocyte, the synthesis of melanin as responsible for skin pigmentation and the action of mandelic peeling as a depigmenting active. The methodology used was the bibliographic study that consists of collecting information based on studies pre-existing information available in books, articles and websites related to health. After the selection of the study material, the reading, thorough analysis and interpretation of the information was carried out, providing support for the data file and consequent theoretical foundation. From the analysis of the information, it can be concluded that hyperchromias are the result of several factors and that mandelic acid is a less aggressive option for the treatment of this dysfunction, presenting satisfactory results. Since it is a molecule with high weight, its permeation is slower and more uniform, acting as a collagen stimulator, however, its indiscriminate use can cause burns, bruises and other adverse effects, making its administration by trained personnel advisable.
\end{abstract}

Keywords: Epidermis; Hyperchromias; Melanogenesis; Mandelic Acid.

Topic: Controle de Fármacos e Medicamentos

Reviewed anonymously in the process of blind peer.
Received: $18 / 02 / 2020$

Approved: 08/05/2020

Izis Moara Morais Leão Nolasco (id

Instituto de Excelência em Educação e Saúde, Brasil

http://lattes.cnpq.br/9863704607661803

izismoaramorais@gmail.com

Juliana Resende Resende (id

Instituto de Excelência em Educação e Saúde, Brasil

http://lattes.cnpq.br/1655276774905822

julianaresende30@gmail.com

Referencing this:

NOLASCO, I. M. M.; RESENDE, J. R.. Uso do ácido mandélico no tratamento de hipercromias pós-inflamatória: uma revisão de literatura. Scire Salutis, v.10, n.2, p.35-42, 2020. DOI: http://doi.org/10.6008/CBPC2236-9600.2020.002.0005 


\section{INTRODUÇÃO}

A preocupação com a pele vem aumentando significativamente nas últimas décadas e, disfunções como as discromias (alterações na pigmentação cutânea) estão entre as principais causas de queixa dos indivíduos que procuram serviços estéticos. As discromias podem ser divididas em hipocromias (diminuição na produção de melanina), acromias (ausência total de melanina) e hipercromias (aumento da produção de melanina), que, por ser a mais frequente, será objeto de revisão nesta pesquisa (SIMAS, 2014).

Gonchoroski et al. (2005) explicam que "as hipercromias são desordens de pigmentação que tem origem numa produção exagerada de melanina". Essas manchas podem surgir devido a fatores como o envelhecimento, alterações hormonais, inflamações, alergias e exposição solar.

Simas (2014) classifica as hipercromias em: Melasma ou cloasma; Efelides ou sardas; Fitofotomelanose; Melanose solar; Hiperpigmentação pós-inflamatórios, no entanto, é importante salientar que nem toda hipercromia se trata apenas de disfunção estética, em alguns casos pode ser indicativo de alguma patologia como infecções fúngicas e até neoplasias, nestes casos, não cabe ao profissional de estética realizar quaisquer procedimentos.

Como forma de tratamento são utilizadas substancias clareadoras ou despigmentantes, e o uso de peelings químicos está no topo da lista dos procedimentos para tratar tais disfunções, podendo ser definido como "[...] aplicação de agentes que destroem as camadas superficiais da pele, seguindo-se então da sua regeneração, com uma aparência geral melhorada" (SBD, 2017).

Dentre as opções de agentes disponíveis no mercado, o peeling mandélico se destaca por ser mais suave que os demais ácidos e por apresentar resultados satisfatórios no clareamento de manchas, tratamento de acne através da ação antibacteriana e antisséptica, e ainda ação anti-aging, provocando uma descamação mais suave, acelerando a regeneração tecidual e estimulo de colágeno (SILVA et al., 2017).

Fazendo parte dos Alfa-hidroxi-ácidos ou AHAS, o ácido mandélico tem origem orgânica e é obtido a partir da hidrolise do extrato das amêndoas amargas e por possuir maior peso molecular, penetra mais lentamente na pele, promovendo a despigmentação através da inibição da síntese de melanina (SOUSA et al., 2018).

Outro ponto considerado na escolha do tema deve-se ao fato de o ácido mandélico realizar a despigmentação de forma segura em todos os fototipos, evitando o tão temido efeito rebote. Dito isto, o presente artigo visa abordar a partir da revisão de literatura a estrutura da epiderme e do melanócito, a síntese da melanina como responsável pela pigmentação cutânea e a ação do peeling mandélico como ativo despigmentante.

\section{METODOLOGIA}

A metodologia utilizada foi o estudo bibliográfico que consiste na coleta de informações se baseando em estudos pré-existentes disponíveis em livros, artigos e sites inerentes à área da saúde. Após a seleção do material de estudo, foi realizado a leitura, análise minuciosa e interpretação das informações, dando subsídio 
para o fichamento de dados e consequente fundamentação teórica. Ao todo, serviram de material de pesquisa, 35 artigos, que após passar pelo critério de inclusão, baseado em artigos que retratavam a fisiologia do melanócito, a fisiopatologia das hipercromias e a ação do ácido mandélico na hiperpigmentação, formaram um grupo de 15 artigos.

\section{DISCUSSÃO TEÓRICA}

\section{Tecido Cutâneo}

Para melhor compreender a ação do peeling mandélico sobre o melanócito, é preciso recordar alguns aspectos importantes da anatomia e fisiologia da pele, mas especificamente sobre a epiderme, tecido onde essas células ficam localizadas. Sendo o maior órgão do corpo humano, a pele, ou tecido cutâneo, representa cerca de $5 \%$ do peso corporal e é dividido em três camadas: a epiderme (superficial), a derme (intermediária) e a hipoderme (camada mais profunda), apresentando as funções de termorregulação, nutrição, proteção, queratogenese e pigmentação, além da regulação homeostática e função sensitiva (SILVA JUNIOR et al., 2017).

Como supracitado, os melanócitos ficam alojados na epiderme, camada mais superficial da pele humana, que pode ser dividida em 4 ou 5 camadas dependendo da região corporal, sendo elas (DELAY et al., 2018): 1 Estrato córneo: células não possuem núcleos e nem organelas e com citoplasma cheio de queratina; 2 Estrato lúcido; células eosinofilicas queratinizadas (camada fina) - pele espessa como a palma da Mao e planta dos pés; 3 Estrato granuloso: células achatadas camada mais superficial de células nucleadas (3-5 camadas); 4 Estrato espinhoso: células poliédricas a pavimentosas (várias camadas de pele); 5 Estrato basal: células germinativas ( 1 camada) onde se localizam os melanócitos. O corte histológico da epiderme pode ser observado na figura 1.

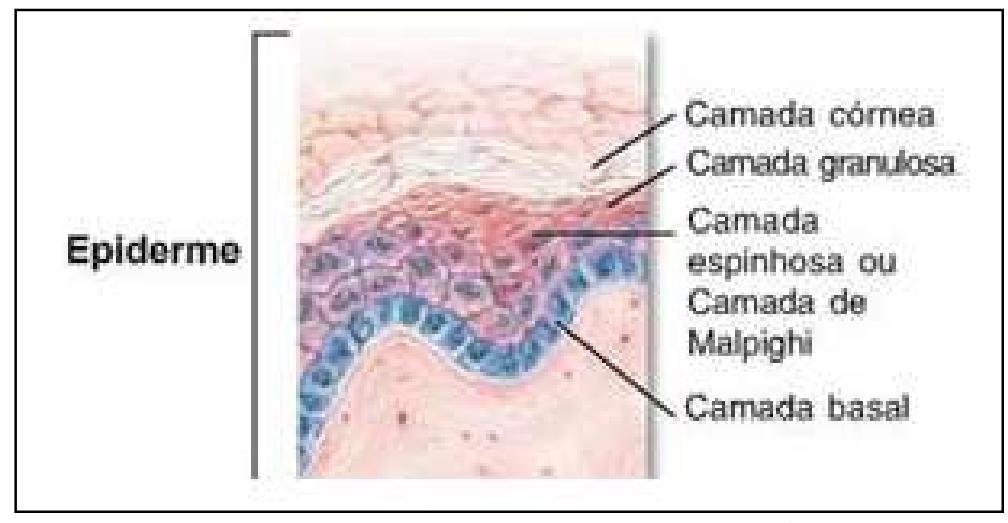

Figura 1: corte histológico da epiderme. ${ }^{1}$

É conhecido que a epiderme tem origem embriológica no ectoderma e é formada pela justaposição celular, já os melanócitos se originam na crista neural e migram para a epiderme a partir da 8o semana de gestação, onde inicia sua ação, sofrendo um declínio em suas funções a partir dos 30 anos de idade devido à perda do poder melanogenico por mecanismos intrínsecos ao bulbo piloso, não havendo alterações da

${ }^{1}$ https://player.slideplayer.com.br/1/294029/data/images/img7.png 
melanina já presente na epiderme (MIOT et al., 2009).

\section{Melanócitos e melanogênese}

$\mathrm{Na}$ idade adulta, os melanócitos estão dispostos na camada basal e representam cerca de 5 a $13 \%$ das células da epiderme, sendo responsáveis pela produção da melanina, substancia polimérica derivada da tirosina que confere a cor da pele, olhos e cabelos e exibindo a capacidade de responder a estímulos externos como a radiação ultravioleta, estímulos parácrinos e endócrinos pela ação hormonal (FILIPPIN, 2013).

Estimasse que, quanto maior o deposito de melanina nos queratinócitos, mais escuro será a tez e tendo a melanina capacidade de absorver os raios UV provenientes do sol, protegendo o núcleo das células, o que torna estes indivíduos menos propensos ao desenvolvimento de lesões celulares ou danos ao material genético (FILIPPIN, 2013). A estrutura do melanócito e o deposito de melanina no queratinócito pode ser observada na figura 2.

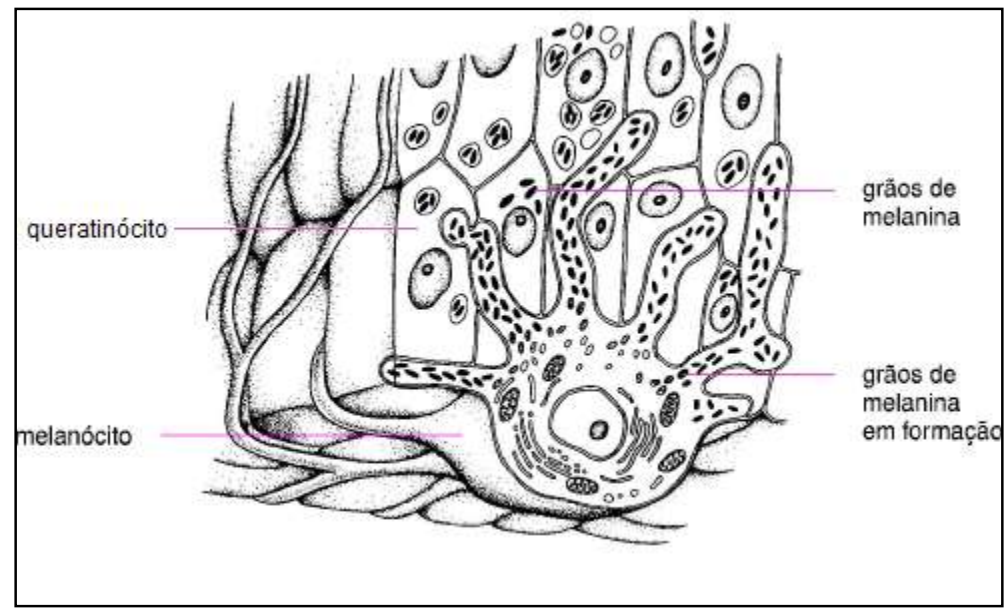

Figura 2: estrutura do melanócito. ${ }^{2}$

É sabido que na pele humana existem basicamente dois tipos de melanina: a eumelanina e a feomelanina, além das mistas, formadas pela junção de frações das duas já citadas. Harrys (2003) explica que,

As diferentes tonalidades de pele observadas entre os tipos étnicos são fruto da variação entre as proporções relativas desses pigmentos: maior concentração de eumelanina nos indivíduos com a pele mais escura e cabelos negros ou castanhos, e maior concentração de feomelanina em pessoas ruivas ou loiras.

As eumelaninas apresentam tonalidade do marrom ao preto, são insolúveis na maioria dos solventes e se associam as proteínas através de ligações covalentes. Além disso, por apresentar em sua estrutura uma subunidade semiquinona, participam ativamente das reações oxidantes como redutoras e interação com radicais livres e outros sistemas de oxirredução, por esse motivo são responsáveis pala proteção de células basais contra a ação dos raios UV (HARRIS, 2003).

Por outro lado, as feumelaninas apresentam tonalizantes que vão do amarelo ao vermelho, e, por serem foto lábeis, sofrem degradação quando expostas a radiação UV, originando através da fotólise

\footnotetext{
${ }^{2}$ http://bioqdocancer.blogspot.com/2011/11/melanoma.html
} 
espécies reativas de oxigênio, intensificando os danos da radiação (HARRIS, 2003). A L-tirosina é o aminoácido responsável pela síntese de melanina e é sintetizado geralmente no citosol pela hidroxilação da Lfenilalamina. Após esse processo a L-tirosina é transportada para dentro dos melanossomas, dando início a melanogenese (GONCHOROSKI et al., 2005). A rota biossintética da melanogênese pode ser observada na figura 3.

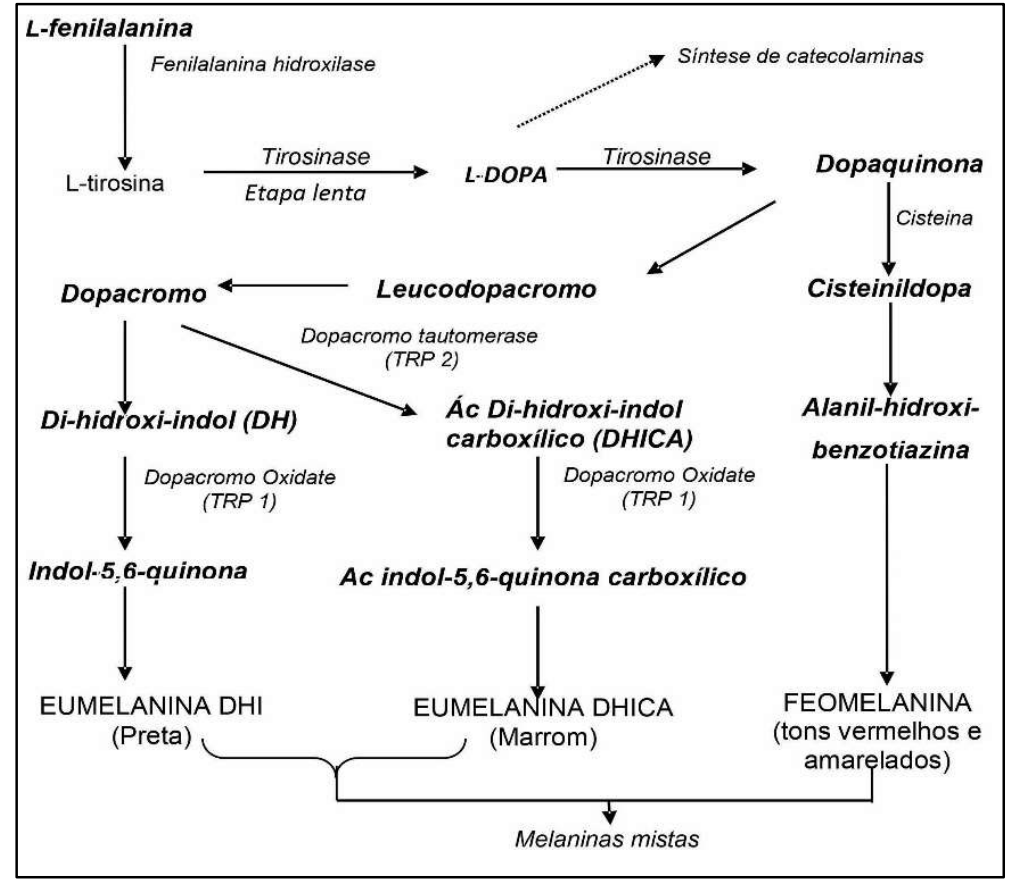

Figura 3: Esquema da rota biossintética para produção de melanina. Fonte: adaptado de Harris (2003).

O primeiro estágio da relação epidérmico-melânico se inicia com a organização da matriz dos melanócitos para a criação dos melanossomas. Esse processo envolve a interação entre o reticulo endoplasmático e complexo de Golgi. Consequente, segundo Harris (2003): 1 Transcrição das enzimas da melanogenese e formação das vesículas e comporão os melanossomas; 2 Formação da matriz fibrilar com formação inativa das enzimas melanogenicas (já se observa ação da feumelanina); 3 Início da síntese de eumelanina com ativação da tirosinase e outras enzimas; 4 Melanócitos desenvolvidos e repletos de melanina; 5 Transporte ativo dos melanossomas até os queratinócitos, onde são fagocitados pelos receptores protease-ativados 2 .

E ainda, a conversão de Dopa em Dopaquinona que se dá espontaneamente em pH fisiológico, estando todo o processo em controle genético. Resumidamente, a melanina sendo sintetizada no melanossomos, com a projeção dos dendritos através das camadas malpighiana e deposito de melanina nos queratinócitos, processo denominado relação epidérmico-melânica e nos seres humanos é constituída pela junção de 1 melanócito para cerca de trinta e cinco queratinócitos (RUBIN et al., 2006).

Como mencionado, a pigmentação da pele se deve a ação da melanina sobre o queratinócito, desde modo, a hiperpigmentação acontece quando ocorre um desequilíbrio em um ou todos os estágios da melanogenese, visto que a mesma sofre influência de diferentes fatores, como genética (característica dos melanossomos definidos pelos genes de pigmentação), ação de hormônios (hormônio hipofisário) e exposição aos raios UV (NICOLETTI et al., 2002). Sobre o estímulo na produção da melanina por exposição 
aos raios UV, Gonchoroski et al. (2005) evidenciam que:

A produção aumentada de melanina em decorrência da estimulação direta ou indireta é uma reação defensiva da pele a fim de proteger-se contra as radiações solares. Após a irradiação os melanossomas se reagrupam em torno do núcleo a fim de proteger o material genético da célula, e assim, além de promover a coloração da pele, cabelo e pelos, a melanina promove foto proteção, agindo como um filtro solar, difratando ou refletindo a radiação solar.

É valido compreender o processo de formação da melanina, pois, para que se escolha um tratamento eficaz para as hipercromias, faz-se necessário entender suas causas e fatores desencadeantes. Outro ponto chave no tratamento de hipercromias consiste no local de origem das mesmas, ou seja, se a pigmentação está vindo da epiderme ou se o deposito da melanina provém da derme.

Geralmente, manchas castanhas resultam do aumento no deposito de melanina da epiderme e se dá pelo aumento na atividade e do número de melanócitos secretores, além da elevação da quantidade e tamanho dos melanossomas. As manchas provenientes da derme se apresentam em tons azul-acinzentados e se devem a presença de melanina em melanócitos ou macrófagos dérmicos (GONCHOROSKI et al., 2005).

\section{Peeling mandélico}

O ácido mandélico foi descoberto pelo farmacêutico alemão Ferdinand Ludwig Winckler, em 1831 e ganhou esse nome devido ser extraído do extrato das amêndoas. Logo após sua descoberta o composto orgânico começou a ser amplamente utilizado na formulação de medicamentos e como agente antibacteriano no tratamento de infecções geniturinárias (FILIPPIN, 2013).

Trata-se de um Alfa-hidroxi-ácido lipossolúvel, ou seja, solúvel em meio oleoso, o que o torna ideal para peles oleosas. Possui 8 carbonos, sendo representado pela fórmula química $\mathrm{HOCH}(\mathrm{C} 6 \mathrm{H} 5) \mathrm{COOH}$ (PIMENTEL, 2008). Atualmente, o produto ganhou espaço entre os profissionais de dermatologia e estética como tratamento eficaz e pouco agressivo dos sinais do envelhecimento cutâneo e hipercromias, principalmente por acelerar a taxa de renovação celular, eliminando células mortas (MOURA et al., 2017).

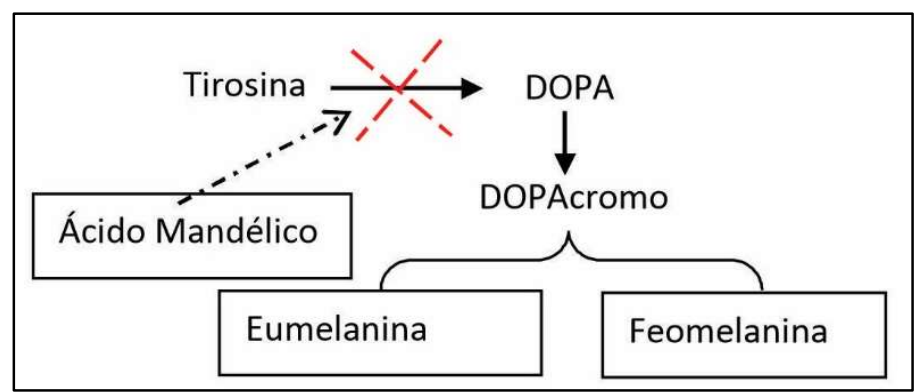

Figura 4: Inibição da melanogenese pela ação do ácido mandélico. Fonte: adaptado de Harris (2003).

Caracterizado no grupo de peelings superficiais, seu uso apresenta melhores resultados quando aplicados de forma seriadas e em curto período de tempo, causando uma descamação fina e clara. Esse processo produz uma melhora na textura da pele e consequente clareamento de manchas, atenuando rugas finas e estimulando a produção de colágeno. O conhecimento do mecanismo da síntese de melanina torna mais fácil compreender como ocorre a inibição da melanogenese. No caso do uso do ácido mandélico, o processo de clareamento acontece através da inibição da síntese de tirosina, como se observa na figura 4 
(HARRIS, 2003).

O ácido mandélico inibe a tirosinase e consequentemente a formação da melanina, fazendo com que menos pigmento se deposite nos queratinócitos. Possui também ação absolutória, dissolvendo o pigmento já depositado A concentração cosmética do ativo é de no máximo $10 \%$, podendo ser associado a outros ativos para melhores resultados (MARQUES, 2016). O quadro 1 apresenta as principais indicações do ácido mandélico dentro da estética e saúde.

Quadro 1: Indicações do uso do Ácido Mandélico.

\begin{tabular}{|l|l|}
\hline Indicação & Mecanismo de ação \\
\hline Prevenção e tratamento de acne & $\begin{array}{l}\text { Apresenta propriedades bactericidas, ajudando inclusive na foliculite causada } \\
\text { por gram-negativos. }\end{array}$ \\
\hline Hiperpigmentação solar & $\begin{array}{l}\text { Inibição da síntese de melanina e na melanina já depositada na pele, agindo na } \\
\text { remoção dos pigmentos hipercromicos. }\end{array}$ \\
\hline $\begin{array}{l}\text { Hiperpigmentação pós-inflamatória e } \\
\text { Melasma }\end{array}$ & Inibição da enzima tirosinase. \\
\hline Antienvelhecimento & Penetra na derme estimulando a produção de colágeno. \\
\hline Esfoliante. & Dissolvendo o cimento intercelular, causando descamação. \\
\hline
\end{tabular}

Fonte: Adaptado de Pimentel (2008).

Outro fator importante a ser considerado, se deve ao fato do ácido mandélico ser bem menos irritante que outros AHAS, como o ácido glicólico e ácido lático, por exemplo. Isso permite que seja utilizado com segurança em peles sensíveis e em todos os fototipos. Sousa et al. (2018) acrescentam que:

Este ácido é o mais indicado para peles oleosas, acneicas e morenas. A sua utilização no tratamento de peeling garante rejuvenescimento, afinando as linhas finas e marcas de expressão, trata a acne, clareia as manchas e melhora a textura da pele. $O$ efeito produzido pelo uso desse ácido pode provocar uma leve ardência e um pouco de descamação

Mesmo se tratando de um ácido relativamente seguro para todos os fototipos, é sempre valido ressaltar que o produto se tona mais eficaz quando aplicado de forma controlada e por pessoa qualificada, uma vez que é um produto químico cujas ações podem trazer consequências irreversíveis em caso de má utilização.

Entre as reações adversas o indivíduo pode apresentar eritema severo, inchaço na área dos olhos, queimação, formação de bolhas, sangramento, erupções e coceira, sendo de maior ou menor intensidade conforme a concentração do ácido e sensibilidade cutânea (MARQUES, 2016). O mecanismo de ação dos AHAS ainda não é completamente conhecido, o que se sabe é que o ácido mandélico age na inibição da tirosinase pré e pós-depositada, ajudando a promover uma remoção do pigmento já depositado no queratinócito (DELAY et al., 2018).

O produto é contraindicado em caso de gestação ou lactação. Pessoas com lesões na região a ser tratada ou com herpes ativa e que apresentem sensibilidade ao ativo também não devem fazer uso. Ressaltase ainda que o uso do ácido mandélico em associação a outros ácidos é desaconselhando sem a avaliação de um dermatologista, visto que podem interagir causando irritação extrema e danos irreversíveis (MOURA et al., 2017).

\section{CONCLUSÕES}

Com a realização deste estudo foi possível constatar que diversos autores descrevem o ácido 
mandélico como um produto seguro e eficaz no tratamento de hipercromias, podendo ser utilizado isoladamente ou em associação a outros ativos. As pesquisas sugerem também que, por se tratar de uma molécula com alto peso, sua permeação é mais lenta e uniforme, agindo como um estimulador de colágeno, no entanto, seu uso indiscriminado pode acarretar queimaduras, equimoses e outros efeitos adversos, tornando aconselhável sua administração por pessoal capacitado.

A pesquisa bibliográfica nos leva a concluir que, apesar de diversos benefícios já conhecidos, o ácido mandélico ainda é pouco utilizado em comparação a outros ácidos mais agressivos como o retinóico e o glicólico, o que ressalta a importância dos estudos acerca do tema abordado. Salienta-se ainda que, independente da segurança do produto ou de sua eficácia no tratamento de hipercromias, sem o zelo adequado com a pele e uso de foto proteção, qualquer protocolo será falho, cabendo ao profissional instruir seu paciente sobre os devidos cuidados.

\section{REFERÊNCIAS}

DELAY, C. E.; LOPES, M. S.. Peeling de Ácido Mandélico Associado ao Algowhite no Clareamento Cutaneo. Monografia (Bacharelado) - Universidade Federal do Paraná, Curitiba, 2018.

FILIPPIN, F. B.. Avaliação da atividade citotoxica e melanogenica do complexo de platina (II) com derivado de hidantoina em melanoma. Dissertação (Mestrado em ciencias Farmaceuticas) - Universidade de São Paulo, São Paulo, 2013.

GONCHOROSKI, D. D.; CORREA, G. M.. Tratamento de Hipercromias pos-inflamatorias com diferentes formulações clareadoras. Infarma, v.17, n.3, p.84-86, 2005.

HARRIS, M. I.. Pele, estutura, propriedades e envelhecimento. São Paulo: Senac São Paulo, 2003.

MARQUES, C.. Esteticista como você. 2016.

MIOT, L. D.; MIOT, H. A.; SILVA, M. G.; MARQUES, M. E.. Fisiopatologia do meslasma. In: BRASILEIRO DE DERMATOLOGIA. Anais. 2009. p.623-635.

MOURA, M. C.; MIRANDA, J.; GRIGNOLI, L. C.; SEGATIN, J. D.. $\mathrm{O}$ uso de acido e ativos aclareadores associados ao microagulhamentono tratamento de manchas hipercromicas: Estudo de caso. Revista científica da FHO UNIARARAS, v.5, n.2, p.34-44, 2017.
NICOLETTI, M. A.; ORSINE, E. M.; DUARTE, A. C.; BUONO, G. A.. Hipercromias: aspecctos gerais e uso de despigmentantes cutaneos. Cosmetics \& Toiletries, v.14, p.46-51, 2002.

PIMENTEL, A. D.. Peeling, máscaras e acne: seus tipos e passo a passo do tratamento estetico. São Paulo: Livraria Médica Paulista, 2008.

RUBIN, E.; GORSTEIN, F.; RUBIN, R.; SCWARTING, R.; STRAYER, D.. Patologia: bases clínicas e patologicas da medinica. Rio de Janeiro: Koogan, 2006.

SBD. Sociedade Brasileira de Dermatologia. Peeling e suas classificações. SBD, 2017.

SILVA JUNIOR, A. A.; SILVA, R. P.; SILVA, V. L.; PAULINO, E. N.. Tratamento da Acne Vulgar a Partir de Peelings Químicos e Principais Ácidos Aplicados. Monografia (Bacharelado)Universidade Federal de Pernambuco, Caruaru, 2017.

SILVA, E. G.; VARGAS, A.. Painel científico. 2017.

SIMAS, L. A.. Peeling oral. In: CONGRESSO BRASILEIRO DE NUTRIÇÃO ESTETICA, 2. Anais. 2014. p.1-6.

SOUSA, A. F.; SILVA, M. J.. Euroamerica instituto técnico profissional. Euroamerica, 2018.

A CBPC - Companhia Brasileira de Produção Científica (CNPJ: 11.221.422/0001-03) detém os direitos materiais desta publicação. Os direitos referem-se à publicação do trabalho em qualquer parte do mundo, incluindo os direitos às renovacões, expansões e disseminacões da contribuiç̃o, bem como outros direitos subsidiários. Todos os trabalhos publicados eletronicamente poderão posteriormente ser publicados em coletâneas impressas sob coordenação da Sustenere Publishing, da Companhia Brasileira de Produção Científica e seus parceiros autorizados. Os (as) autores (as) preservam os direitos autorais, mas não têm permissão para a publicação da contribuição em outro meio, impresso ou digital, em português ou em tradução. 